\title{
Experimental studies on the pathogenesis of retinopathy of prematurity
}

\author{
MAREK PROST \\ From the Clinic of Ophthalmology, Medical Academy in Lublin, Poland
}

SUMMARY The angiogenic activity of various parts of the retina in kittens with oxygen-induced retinopathy has been studied by the use of a corneal micropocket technique and chorioallantoic assay. The results indicate that in retinopathy of prematurity the most important role in the pathogenesis of fibrovascular proliferation is played by the so-called primary avascular retina, that is, that part of the retina which has not yet been vascularised during ontogenesis.

Retinopathy of prematurity is one of the proliferative retinopathies, and is a significant cause of blindness in children. The primary pathological change in this disease is peripheral fibrovascular proliferation of the retina. It is thought that this proliferation is caused by diffusable biochemical substances which possess angiogenic properties. These substances are presumably liberated in the ischaemic and, as a result, hypoxic retina.' In most proliferative retinopathies the development of neovascularisation is preceded by the appearance of retinal ischaemic areas (capillary non-perfusion areas) which can be detected by fluorescein angiography. In retinopathy of prematurity areas of capillary non-perfusion can be found angiographically in the areas of oxygen induced obliteration of immature capillaries..$^{23}$ These areas of the retina have for a long time been considered as sites of liberation of angiogenic substances causing fibrovascular proliferation in retinopathy of prematurity. ${ }^{145}$ In retinopathy of prematurity, however, in contrast to other proliferative retinopathies, there are two kinds of avascular retinal tissue: the primary avascular retina in the periphery where retinal vessels have not yet been formed during ontogenesis, and the secondary avascular retina at the site where the vessels have been destroyed by oxygen (Fig. 1). During intrauterine life the primary avascular retina is in a state of mild hypoxia, which is believed to stimulate the growth of the vessels into it. ${ }^{6}$ Following oxygen administration to premature infants mesenchymal tissue ceases to penetrate the originally avascular retina. Thus it may be assumed that this part of the

Correspondence to Marek Prost, MD, Clinic of Ophthalmology, Chmielna 1, 20-079 Lublin, Poland. retina becomes more and more anoxic with the lapse of time. It therefore seems possible that angiogenic factors are also produced in the primary avascular retina.

This paper reports a study of the activity of the primary and secondary avascular retina of kittens with oxygen induced retinopathy.

\section{Material and methods}

Studies were carried out on eight adult female cats and their 27 newborn kittens. Proliferative retinopathy was induced in the kittens by placing them on the second day of their life in an $80 \%$ oxygen environment for $72 \mathrm{~h}$. They were then moved to room

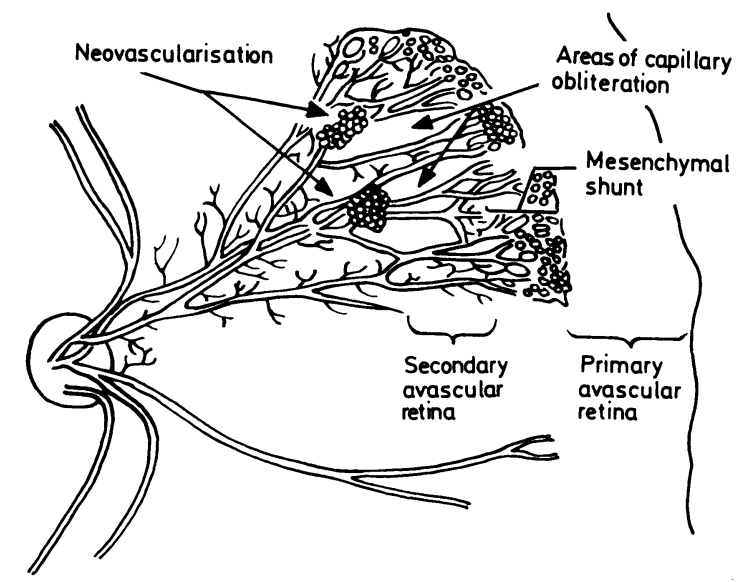

Fig. 1 Scheme of retinal changes in the initial active stages of retinopathy of prematurity. 
air until day 21 of life. After this period in eight kittens the retina was excised under the microscope, and $1.5 \times 1.5 \mathrm{~mm}$ sections were prepared in the primary and secondary avascular retina according to the technique of Federman et al. ${ }^{7}$ The sections of each kitten's retina were implanted immediately into the $3 \times 4 \mathrm{~mm}$ pockets of their mother's cornea, made according to the technique of Gimbrone et al. ${ }^{8}$ The distal margin of the pocket was $1 \mathrm{~mm}$ from the corneal limbus. The pockets were not made in the axis of rectus muscles, where the sclera is more extensively vascularised. ${ }^{9}$ Two pockets were made in each eye. In the right eye retinal sections from the primary avascular retina were implanted into the pockets, whereas in the left eye were implanted those from the secondary avascular retina. For grading the proliferation of vessels in the cornea the author used his own four-grade scale.

In 19 other kittens the retina was also prepared and its sections were implanted into the chicken chorioallantoic membrane of 40 embryos. In 20 of them the sections came from the primary avascular retina and in 20 from the secondary avascular retina. Implantations were performed according to the technique of Lutty et al. ${ }^{10}$ The rate of inward growth of the membrane vessels was graded by the author's fourgrade scale worked out for this purpose.

Because of the small amount of available material retinal extracts could not be made. Therefore, whole sections of the retina were implanted in both procedures.

In the control group, in which proliferative retinopathy was not induced, studies were carried out on eight mother cats and their 21 2-day-old kittens, 80 chicken embryos, and four adult cats. Two-day-old kittens were used because, as observations had shown, the size of their peripheral avascular retina corresponded to that of the primary avascular retina in kittens with proliferative retinopathy. In 21-dayold normal kittens the retina was almost totally vascularised, and hence it was impossible to carry out studies. In eight kittens sections were prepared from the peripheral avascular part of the retina. These were implanted into the pockets in the cornea of the right eye of the kittens' mother, while sections from the peripheral part of the vascularised part of the retina were implanted into pockets in the left eye of their mothers. In the same way retinal sections were prepared in the other 13 kittens and grafted into the chorioallantoic membrane of 40 chicken embryos (20 with peripheral avascular and 20 with peripheral vascularised retina). In four adult cats only pockets were made in the cornea, without tissue grafting. In addition sections of normal kitten's cornea were grafted to the chorioallantoic membrane in 20 chicken embryos and sections of the chorioallantoic membrane in the other 20 chicken embryos. The results were statistically analysed by Student's $t$-test.

\section{Results}

Evaluation of neovascular growth of limbal vessels after grafting of the studied tissues into a corneal pocket. After 4-5 days the vessels of the limbus started to invade the cornea at the site of the pocket. After 7-8 days they reached the tissue graft in the pocket. Their maximum growth was visible after about 12 days, and from day 21 their slow disappearance was observed. The extension of vessels in the cornea was graded on day 14 on the basis of a fourgrade scale developed on the basis of observations of the cornea with grafted tissues. The individual grades corresponded to the following changes in the cornea.

0 : No penetration of vessels into the cornea.

I: Single vessels not more than 5 visible in the cornea in area of the pocket.

II: The number of extending vessels exceeded 5, but they were present only in the area of the pocket (Fig. 2).

III: Further increase in the number of vessels

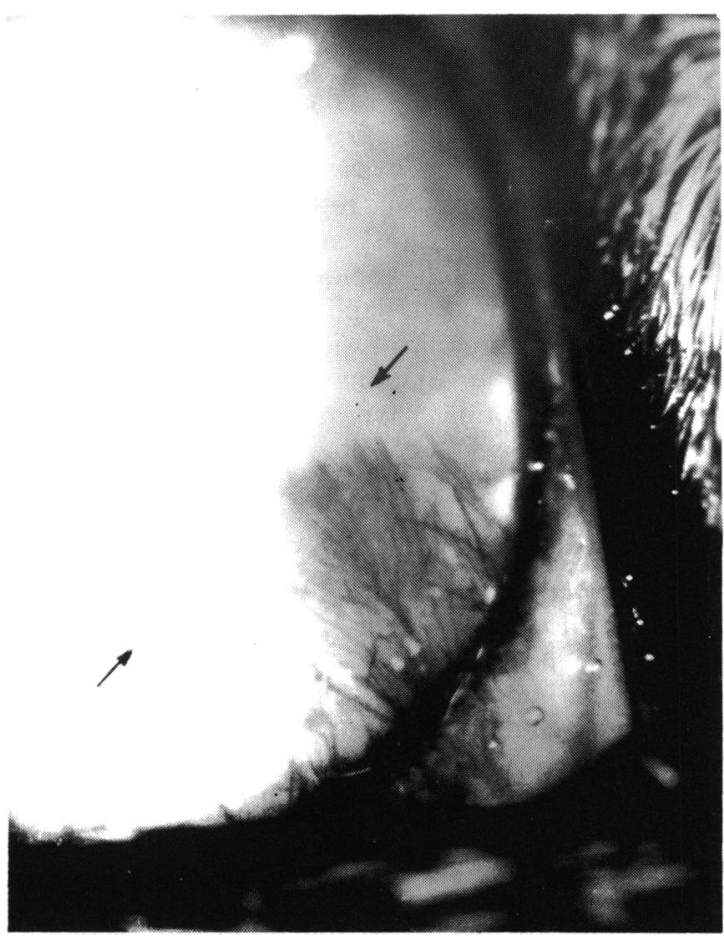

Fig. 2 II of neovascularisation after grafting of secondary avascular retina of kittens with oxygen induced retinopathy into a corneal pocket (size of the pocket marked by arrows). 
Table 1 Neovascular response of limbal vessels after grafting of the studied tissues into a corneal pocket

\begin{tabular}{lllllll}
\hline No. & Kind of grafted tissue & $n$ & Mean $S D$ & $p$ \\
\hline 1 & $\begin{array}{c}\text { Primary avascular retina in kittens with } \\
\text { oxygen induced retinopathy }\end{array}$ & 16 & 2.93 & 0.68 & $\mathrm{a}^{*}$ \\
2 & $\begin{array}{c}\text { Secondary avascular retina in kittens with } \\
\text { oxygen induced retinopathy }\end{array}$ & 16 & 2.56 & 1.03 & $\mathrm{a}$ \\
3 & $\begin{array}{c}\text { Avascular peripheral retina of normal } \\
\text { kittens }\end{array}$ & 16 & 0.87 & 0.50 & $\mathrm{~b}$ \\
4 & $\begin{array}{l}\text { Vascular peripheral retina of normal } \\
\text { kittens } \\
\text { Corneal pocket without grafted retinal } \\
\text { tissue }\end{array}$ & 16 & 2.50 & 0.96 & $\mathrm{a}$ \\
5 & 16 & 0.00 & & $\mathrm{c}$
\end{tabular}

*Means with different letters differ significantly $(p<0.001)$ from each other.

which extended also to parts of the cornea adjacent to the pocket.

IV: The width of the front of the invading vessels was twice as large as the width of the pocket in the cornea.

The results in grades ( 2 from each eye) were summed up in each animal group and the mean was calculated (Table 1).

Evaluation of neovascular response of the chorioallantoic membrane after grafting of the tissues. The extent of blood vessels penetration was determined on the basis of a four-grade scale which was developed from observations of the chorioallantoic membrane with grafted tissues. The individual grades of the scale corresponded to the following changes of blood vessels of the chorioallantoic membrane.

0 : No changes in the configuration of blood vessels.

I: Concentric penetration of small vessels of the membrane into the grafted tissue was seen, but the changes observed did not cover in all more than two quadrants.

II: Penetrating blood vessels were found in all quadrants of the membrane surrounding the grafted tissue. Changes were also observed in the course of medium vessels.

III: Further medium blood vessels of the membrane started to penetrate the graft (Fig. 3).

IV: Concentric penetration of big vessels into the grafted tissue could be seen, which often formed extended loops in the centre.

The results obtained in the grades were summed up in each group of animals and the mean was calculated (Table 2).

\section{Discussion}

The corneal micropocket technique and chorioallantoic assay are widely used by many investigators

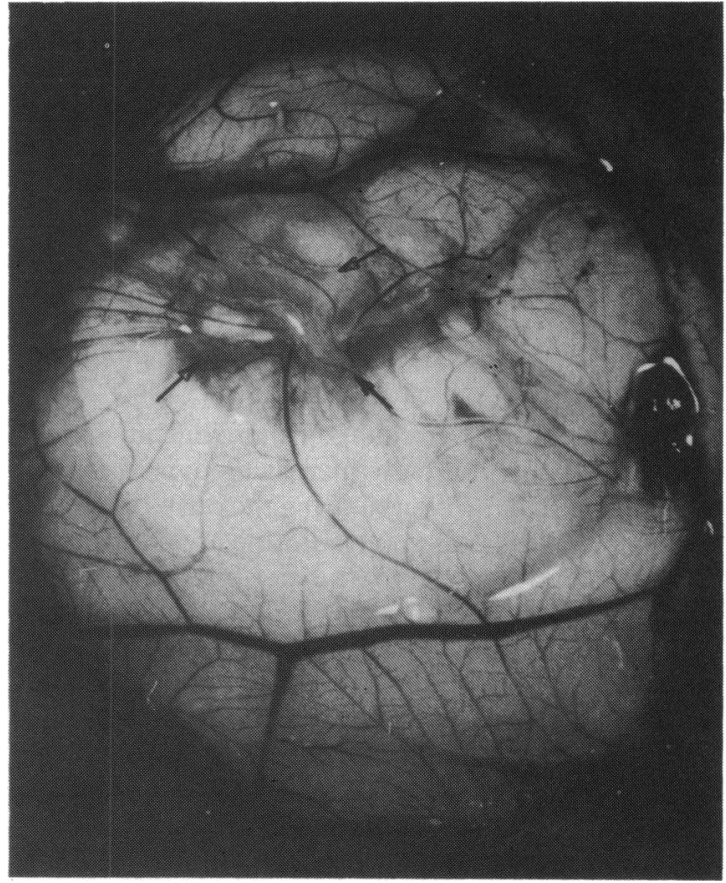

Fig. 3 III of neovascularisation after grafting of primary avascular retina of kittens with oxygen induced retinopathy on chicken chorioallantoic membrane (site of graft indicated by arrows).

in studies of angiogenic activity of various tissues. ${ }^{17-10} 0^{12-14}$ These two assay systems have therefore been used to study this activity in the primary and secondary avascular retina of kittens. The studies showed that, in oxygen treated kittens with proliferative retinopathy, angiogenic activity of the primary

Table 2 Neovascular response of chorioallantoic membrane after grafting of the studied tissue

\begin{tabular}{llllll}
\hline No. & Kind of grafted tissue & $n^{*}$ & Mean $S D$ & $p^{\dagger}$ \\
\hline 1 & $\begin{array}{c}\text { Primary avascular retina in kittens with } \\
\text { oxygen induced retinopathy }\end{array}$ & 14 & 2.42 & 0.85 & $\mathrm{a}$ \\
2 & $\begin{array}{c}\text { Secondary avascular retina in kittens with } \\
\text { oxygen induced retinopathy }\end{array}$ & 14 & 2.53 & 0.90 & $\mathrm{a}$ \\
3 & $\begin{array}{c}\text { Avascular peripheral retina of normal } \\
\text { kittens }\end{array}$ & 15 & 0.93 & 0.79 & $\mathrm{~b}$ \\
4 & $\begin{array}{c}\text { Vascular peripheral retina of normal } \\
\text { kittens }\end{array}$ & 13 & 2.30 & 0.75 & $\mathrm{a}$ \\
5 & $\begin{array}{c}\text { Chorioallantoic membrane of chicken } \\
\text { embryo }\end{array}$ & 18 & 0.00 & & $\mathrm{c}$ \\
6 & $\begin{array}{c}\text { Normal cornea of kittens with oxygen } \\
\text { induced retinopathy }\end{array}$ & 17 & 0.00 & $\mathrm{c}$
\end{tabular}

*The number of results in the particular groups is smaller than 20 because some embryos died during studies.

†Means with different letters differ significantly $(p<0.001)$ from each other. 
avascular retina increased considerably (about three times) in comparison with the activity of its anatomically corresponding peripheral avascular retina of control animals. This activity in the primary avascular retina was equal to that of the secondary avascular retina. A similar activity was also observed in the peripheral part of the vascularised part of the retina of control kittens; this area anatomically corresponds to the secondary avascular retina. These results indicate that the major effect of oxygen treatment is a considerable increase in the angiogenic activity of the primary avascular retina.

The reason for the change in angiogenic activity seems to be the gradually increasing hypoxia of the primary avascular retina. During the development of normal retinal vessels in intrauterine life the penetration of blood vessels to the peripheral avascular retina is stimulated by its relative hypoxia occurring during maturation. ${ }^{6}$ However, no considerable hypoxia of the retina arises, because gradually developing blood vessels provide an oxygen supply.

The situation changes if oxygen is administered in excess to a premature infant or an experimental animal. Obliteration of immature blood vessels of the retina causes mesenchymal tissue to cease to proliferate and it accumulates in the form of a mesenchymal shunt (Fig. 1). Although differentiation and maturation of the retina itself are progressing, they are not accompanied by the development of its blood vessels. ${ }^{15}$ In such a condition the retinal tissue becomes more and more hypoxic. Oxygen deficiency leads to disturbances in tissue metabolism and liberation of angiogenic substances. In most cases regression of the ability of the mesenchymal tissue to proliferate is observed, and blood vessels again penetrate into avascular retina, liquidating its hypoxia (known as spontaneous regression). If, however, regression does not occur, hypoxia of the primary avascular retina becomes more critical, which in consequence increases liberation of angiogenic factors in this tissue, as is reported in this paper.

The theory of progressing hypoxia of the primary avascular retina was also confirmed by the experimental studies of Ernst and Goldstick. ${ }^{16}$ These authors found that, in kittens with proliferative retinopathy after oxygen treatment, preretinal oxygen pressures above the avascular retina were close to $0 \mathrm{mmHg}$. This was found to be caused by increased oxygen utilisation by the avascular retina after oxygen treatment, and not by a decreased flow in the choroidal vessels. ${ }^{16}$ Thus it may be assumed that in retinopathy of prematurity maturation of the avascular retina itself is progressing despite the inhibition of vascularisation, which leads to its hypoxia.

The data obtained in this paper indicate that the angiogenic activity was similar in both the primary avascular and secondary avascular retina. It seems, however, that a more important role in the pathogenesis of retinal neovascularisation in retinopathy of prematurity is played by the primary avascular retina. As is known, the severity of proliferative retinopathies depends on the size of the area of retinal ischaemia.' In retinopathy of prematurity the incidence and severity of the disease are directly proportional to the prematurity degree ${ }^{17-19}$ - that is, to the size of the primary avascular retina.

Fibrovascular proliferation in the vitreous may assume very different proportions in retinopathy of prematurity. Changes of similar intensity are also found in diabetic retinopathy. Angiographic studies in this disease show that the occurrence of changes is preceded by the appearance of large areas of capillary non-perfusion.' In retinopathy of prematurity the primary avascular retina is an area of comparable size. The secondary avascular retina covers a small area of the ocular fundus, ${ }^{2}$ and angiogenic factors released in this area could not be the reason for such great changes.

Recent studies of Taylor et al. ${ }^{14}$ showed that extracts of whole retinas from kittens with oxygen induced retinopathy contained about 3 times more angiogenic factors than did extracts of normal retinas from control animals. These studies indicate that in the retina of kittens with proliferative retinopathy after oxygen treatment there exist large areas with considerably raised angiogenic activity, as compared with retinas of healthy animals. These areas cannot be identified with the secondary avascular retina, because the area covered by it is small, and it would not change the angiogenic activity of the total retina. The area of the primary avascular retina is sufficiently large to cause these changes.

Retinopathy of prematurity as a rule does occur once the retina is completely vascularised ${ }^{2022}$ - that is, after the disappearance of the primary avascular retina. Cogan's studies, however, have shown that maturation of retinal blood vessels may last for a longer time after the ora serrata is reached. ${ }^{23}$ Thus, if the occurrence of changes depended on the secondary avascular retina, retinopathy of prematurity could also occur after complete vascularisation of the retina, because immature vessels are still present then.

If it is admitted that in the pathogenesis of retinopathy of prematurity the primary avascular retina has a decisive role, it becomes clear why cicatricial tissue primarily develops in the periphery of the fundus. The ischaemic theory assumes that proliferation of blood vessels and the cicatricial tissue accompanying them develop in the direction of the site in which the concentration of angiogenic factors 
is highest. "In retinopathy of prematurity cicatricial tissue develops first of all above the primary avascular retina. If the angiogenic factors were produced mainly in the secondary avascular retina, cicatricial changes would develop further posteriorly the higher the degree of prematurity, which is not in agreement with clinical observations.

The results of this paper and the above considerations may support the following conception of pathogenesis of retinopathy of prematurity. Destruction of immature retinal blood vessels by oxygen results in inhibition of the development of vasoformative mesenchymal tissue and in stopping normal vascularisation of the peripheral parts of the retina. This causes a gradual increase of hypoxia of the primary avascular retina and increases liberation of angiogenic factors which are responsible for proliferation of blood vessels. Hypoxia and liberation of these factors also occur in the area of the secondary avascular retina. However, this is not of main importance in the pathogenesis of retinopathy of prematurity because of the very small area of this part of the retina.

However, it should be emphasised that the above mentioned conception of pathogenesis of retinopathy of prematurity has not yet been completely proved. It was based on the results of experimental studies in which a corneal micropocket technique and chorioallantoic assay were used. Both tests are liable to wide variations, if only because no two animals are ever exactly alike. One cannot be sure either that the volume of tissue implanted is precisely the same in all the test conditions and that the distance between the corneal implant and the limbus is exactly equal throughout. However, despite these limitations it seems that this conception may be found acceptable.

The results of this paper may also have a practical value. It is widely believed that in proliferative retinopathies destruction of ischaemic areas of the retina were angiogenic factors are liberated may bring the vascular proliferation under control and so arrest the disease. ${ }^{1}$ The present results indicate that destruction of the primary avascular retina-for example, by cryotherapy-should be the most effective method in the treatment of retinopathy of prematurity.

\section{References}

1 Patz A. Clinical and experimental studies on retinal neovascularization. Am J Ophthalmol 1982; 94: 715-43.
2 Flynn JT, O’Grady GE, Herrera JA, Kushner BJ, Cantolino S, Milam W. Retrolental fibroplasia: I. Clinical observations. Arch Ophthalmol 1977; 95: 217-23.

3 Payne JW, Patz A. Fluorescein angiography in retrolental fibroplasia. In: Patz A, Fine SL, eds. Interpretation of fundus fluorescein angiogram. Int Ophthalmol Clin 1977; 17: 121-35.

4 Ashton N. The pathogenesis of retrolental fibroplasia. Ophthalmology 1979; 86: 1695-9.

5 Ashton N, Ward B, Serpell G. Effect of oxygen on developing retinal vessels with particular reference to the problem of retrolental fibroplasia. Br J Ophthalmol 1954; 38: 397-432.

6 Ashton N. Oxygen and the growth and development of retinal vessels. Am J Ophthalmol 1966; 62: 412-35.

7 Federman JL, Brown GC, Feldberg NT, Felton SM. Experimental ocular angiogenesis. Am J Ophthalmol 1980; 89: 231-7.

8 Gimbrone MA Jr, Leapman SB, Cotran RS, Folkman J. Tumor growth and neovascularization: an experimental model using the rabbit cornea. J Natl Cancer Inst 1974; 52: 413-27.

9 Chen C-H, Chen SC. Angiogenic activity of vitreous and retinal extracts. Invest Ophthalmol Vis Sci 1980; 19: 596-602.

10 Lutty GA, Thompson DC, Gallup JY, Mello RJ, Patz A, Fenselau A. Vitreous: an inhibitor of retinal extract-induced neovascularization. Invest Ophthalmol Vis Sci 1983; 23: 52-6.

11 Ben Ezra D. Neovasculogenesis. Triggering factors and possible mechanism. Surv Ophthalmol 1979; 24: 167-76.

12 Glaser BM, D'Amore PA, Michels RG, et al. The demonstration of angiogenic activity from ocular tissues. Ophthalmology 1980; 87: 440-6.

13 Kissun RD, Hill CR, Garner A, Phillips P, Kumar S, Weiss JB. A low-molecular-weight angiogenic factor in cat retina. $\mathrm{Br} J$ Ophthalmol 1982; 66: 165-9.

14 Taylor CM, Weiss JB, Kissun RD, Garner A. Effect of oxygen tension on quantities of procollagenase-activating angiogenic factor present in the developing kitten retina. Br J Ophthalmol 1986; 70: 162-5.

15 Nissenkorn I, Kremer I, Ben-Sira I, Cohen S, Garner A. A clinicopathological case of retinopathy of prematurity (ROP) treated by peripheral cryopexy. Br J Ophthalmol 1984; 68: 36-41.

16 Ernst JT, Goldstick TK. Retinal oxygen tension and oxygen reactivity in retinopathy of prematurity in kittens. Invest Ophthalmol Vis Sci 1984; 25: 1129-34.

17 Kalina RE, Karr DJ. Retrolental fibroplasia. Experience over two decades in one institution. Ophthalmology 1982; 89: 91-5.

18 Kinsey VE, Arnold $\mathrm{JH}$, Kalina $\mathrm{RE}$, et al. $\mathrm{PaO}_{2}$ levels and retrolental fibroplasia: a report of the cooperative study. Pediatrics 1977; 60: 655-68.

19 Majima A. Studies on retinopathy of prematurity. I. Statistical analysis of factors related to occurrence and regression in active phase. Jpn J Ophthalmol 1977; 21: 404-20.

20 Patz A. The role of oxygen in retrolental fibroplasia. Graefes Arch Klin Exp Ophthalmol 1975; 195: 77-85.

21 Patz A. Studies on retinal neovascularization. Invest Ophthalmol Vis Sci 1980; 19: 1133-8.

22 Patz A, Payne JW. Retrolental fibroplasia. In: Duane TD, ed. Clinical ophthalmology. Hagerstown: Harper and Row, 1985 update: 3: chapter 20.

23 Cogan D. Development and senescence of the human retinal vasculature. Trans Ophthalmol Soc UK 1963; 83: 465-89.

Accepted for publication 20 March 1987. 